\title{
Warming modifies trophic cascades and eutrophication in experimental freshwater communities
}

\author{
Pavel Kratina, ${ }^{1,6}$ Hamish S. Greig, ${ }^{1,2}$ Patrick L. Thompson, ${ }^{1,3}$ Ticiana S. A. Carvalho-Pereira,,${ }^{1,4}$ and \\ JonATHAN B. Shurin ${ }^{1,5}$ \\ ${ }^{1}$ Biodiversity Research Centre and Zoology Department, University of British Columbia, Vancouver BC V6T $1 Z 4$ Canada \\ ${ }^{2}$ Department of Forest Sciences, University of British Columbia, Vancouver, British Columbia V6T 1 Z4 Canada \\ ${ }^{3}$ Department of Biology, McGill University, Montreal QC H3A 1 B1 Canada \\ ${ }^{4}$ Department of Botany, Federal University of Bahia, Salvador BA 40170115 Brazil \\ ${ }^{5}$ Section of Ecology, Behavior and Evolution, University of California-San Diego, La Jolla, California 92093 USA
}

Abstract. Climate warming is occurring in concert with other anthropogenic changes to ecosystems. However, it is unknown whether and how warming alters the importance of topdown vs. bottom-up control over community productivity and variability. We performed a 16month factorial experimental manipulation of warming, nutrient enrichment, and predator presence in replicated freshwater pond mesocosms to test their independent and interactive impacts. Warming strengthened trophic cascades from fish to primary producers, and it decreased the impact of eutrophication on the mean and temporal variation of phytoplankton biomass. These impacts varied seasonally, with higher temperatures leading to stronger trophic cascades in winter and weaker algae blooms under eutrophication in summer. Our results suggest that higher temperatures may shift the control of primary production in freshwater ponds toward stronger top-down and weaker bottom-up effects. The dampened temporal variability of algal biomass under eutrophication at higher temperatures suggests that warming may stabilize some ecosystem processes.

Key words: climate warming; community structure; food webs; indirect and direct temperature effects; metabolic rates; press perturbations; productivity; temporal variability; trophic interactions.

\section{INTRODUCTION}

Human-induced climate warming is transforming biological communities, yet is only one of a suite of anthropogenic stressors that includes eutrophication, declining predator populations, biotic invasions, and land-use changes (Tylianakis et al. 2008, Ormerod et al. 2010). In addition to its direct impacts, warming can modify communities via synergistic or antagonistic interactions with other changes (Sala et al. 2000, Darling and Côté 2008). While we are beginning to understand how elevated temperature alters the strength of trophic interactions (Barton et al. 2009, O’Connor et al. 2009, Hoekman 2010), it is poorly understood whether warming counteracts or intensifies the impacts of other anthropogenic perturbations on community structure and variability (Montoya and Raffaelli 2010, Woodward et al. 2010). Furthermore, previous work has largely focused on responses of individuals and populations (Walther et al. 2002), and our understanding of interactive temperature effects at a community level is

Manuscript received 31 August 2011; revised 14 December 2011; accepted 10 January 2012. Corresponding Editor: S. P. Lawler.

${ }^{6}$ Present address: Watershed Sciences Center, University of California, One Shields Avenue, Davis, California 95616 USA. E-mail: pkratina@ucdavis.edu rudimentary (Montoya and Raffaelli 2010, Walther 2010).

Physiological, population, and food web studies suggest that ambient temperature may alter the sensitivity of primary producers to eutrophication and predators. Warming has been shown to favor superior competitors for nutrients (Falkowski and Oliver 2007) and to alter species compositions (Winder et al. 2009, Yvon-Durocher et al. 2010). Warming can also exert differential responses of organisms at different trophic levels (Yvon-Durocher et al. 2010), which may alter interaction strengths and move consumer-resource dynamics among stable, cyclic, or chaotic domains (Vasseur and McCann 2005). For example, the respiration rate of heterotrophs can increase more rapidly with temperature than photosynthesis by autotrophs (Allen et al. 2005). In the short term, the greater sensitivity of consumers than producers to temperature change may strengthen top-down control over primary production by increasing grazing rates (O'Connor et al. 2009). Over many grazer generations, however, warming may weaken consumer-resource interactions because metabolic demands of consumers often increase with temperature faster than their feeding rates (Rall et al. 2010), reducing consumer fitness and biomass relative to producers. These potential warming effects on community structure can either reduce or increase temporal 
variability of primary producers in the face of other environmental perturbations.

Adding to this uncertainty, the strengths of bottomup and top-down forces are not likely to be constant over the year, but rather show seasonal changes associated with shifts in ambient temperature. This is particularly true in the shallow lakes and ponds in temperate zones, where plankton communities show pronounced seasonal patterns associated with differences in the timing of events in the producer and consumer communities. Greater sensitivity of higher trophic levels to elevated temperature (Petchey et al. 1999, Vasseur and McCann 2005) could also produce stronger trophic cascades during periods when predators are limited by temperature. Additionally, because warming can favor dense blooms of toxic cyanobacteria (Johnk et al. 2008), elevated temperatures may magnify the effects of eutrophication in summer. Therefore, nonlinear and unequal sensitivities of autotrophs and heterotrophs to temperature may lead to pronounced seasonal changes in the strength of indirect effects of resources and predators in warmer climate regimes.

Here, we factorially manipulated warming $\left(+3^{\circ} \mathrm{C}\right)$, nutrients (nitrogen and phosphorus), and the presence of fish predators (Gasterosteous aculeatus) in freshwater mesocosms to test the impact of elevated temperature (one important manifestation of climate change) on the relative strength of top-down and bottom-up forces. We investigated whether plankton communities respond to environmental perturbations independently, or if interactive effects among multiple perturbations better explain the changes in community structure and dynamics. A synergistic effect implies that communities exposed to warming have lower resistance to other perturbations, while an antagonistic interaction suggests the opposite. In addition to the mean responses, we also compared temporal variability in primary producer biomass among the treatment combinations. This experimental design generated time series of phytoplankton biomass estimates in 40 experimental communities sampled weekly over the 16-month period. Our study therefore encompassed the full annual temperature cycle and enabled us to assess whether the top-down and bottom-up effects of interacting perturbations are constant throughout the year or change seasonally.

\section{Methods \\ Experimental design}

We factorially manipulated temperature, nutrients, and the presence of planktivorous fish in outdoor freshwater experimental mesocosms (1136-L tanks, 0.6 $\mathrm{m}$ deep, $1.5 \mathrm{~m}$ in diameter; Rubbermaid, Sandy Springs, Georgia, USA) situated on a gravel pad at the University of British Columbia, Vancouver, Canada (see Plate 1). The permanently uncovered mesocosms were filled with municipal water and left for one week after filling to allow chlorine to evaporate before the organisms were introduced. Mesocosms were inoculated with zooplankton (cladocerans, copepods, and rotifers), phytoplankton, and microbes from a nearby pond by adding $1 \mathrm{~L}$ of sediment containing spores and eggs, and adding live plankton collected using a 64- $\mu \mathrm{m}$ mesh conical tow net. The experimental communities (total pool of about 50 phytoplankton and 20 zooplankton taxa) increased in densities and assembled from the inoculums and natural dispersal for three weeks prior to the application of treatment perturbations. Submersible water heaters $(300 \mathrm{~W}$; Hagen, Montreal, Quebec, Canada) in one-half of the tanks maintained a continuous $3.04^{\circ} \pm 0.05^{\circ} \mathrm{C}$ (mean $\pm \mathrm{SE}$ ) increase above the ambient daily and seasonal temperature fluctuations of unheated tanks. The water temperature was monitored by HOBO Pendant data loggers (Onset Computer Corporation, Bourne, Massachusetts, USA) in 30minute intervals to ensure that the heaters maintained a consistent temperature difference between the warmed and ambient tanks over the course of the experiment (see Appendix A). This temperature difference falls within the conservative projections of increases in surface water temperatures over the next century (Ramanathan and Feng 2008). We added $264 \mu \mathrm{g}$ of nitrogen/L (as $\mathrm{NaNO}_{3}$ ) and $27 \mu \mathrm{g}$ of phosphorus/L (as $\mathrm{KH}_{2} \mathrm{PO}_{4}$ ) monthly to nutrient addition tanks, resulting in N:P molar ratio of 22. We introduced five threespine sticklebacks (Gasterosteus aculeatus) of standard body length $52.4 \pm 0.05$ $\mathrm{mm} /$ tank (mean $\pm \mathrm{SE}$ ) on 9 June 2009 to initiate predation treatments (see Plate 1). Stickleback have been previously shown to generate trophic cascades by suppressing zooplankton in pond ecosystems (Bell et al. 2003, Harmon et al. 2009). Stickleback that died during the experiment were replaced with similar-sized individuals from the same source population (Woodward Slough, Richmond, British Columbia, Canada). Randomly assigned treatment combinations were replicated five times, resulting in 40 experimental communities. Water levels were maintained throughout the experiment by frequent natural precipitation and additions of equal volumes of filtered water to each tank once during each summer.

Outdoor mesocosms provide a useful intermediary between laboratory microcosms and whole-system experiments. Mesocosms enable controlled manipulation of multiple perturbations with sufficient replication for statistical power, while also providing species diversity, fluctuating environmental conditions, and permeable surface boundaries comparable to natural shallow ponds. Moreover, recent work revealed that the effects of nutrients on primary producers are qualitatively similar in artificial aquatic habitats across five orders of magnitude in size (Spivak et al. 2011). Natural lake ecosystems encompassing a great degree of biotic and structural complexity were studied previously in response to climate warming (Schindler et al. 1990), predator addition, or removal (Carpenter et al. 1985), as well as eutrophication (Schindler 1977). Simultaneous factorial manipulation of all three factors with replica- 

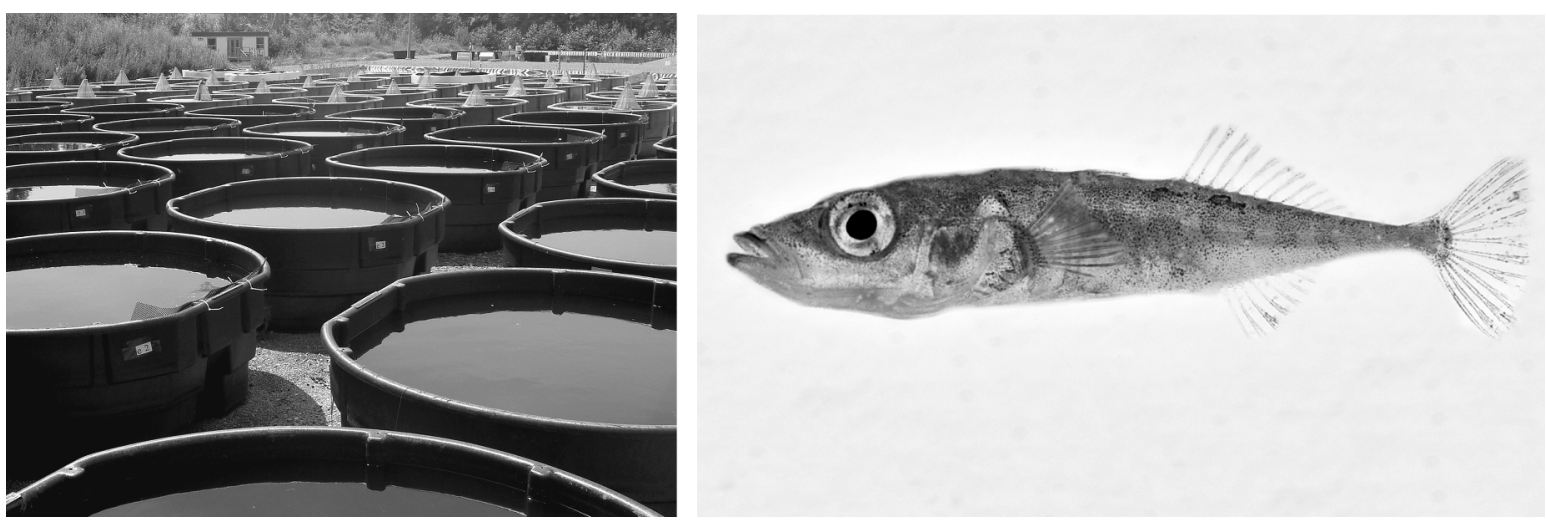

Plate 1. (Left) The experiment was performed in freshwater mesocosms situated at the University of British Columbia, Vancouver, Canada. (Right) Five threespine stickleback (Gasterosteus aculeatus) were used as apex predators in each mesocosm. Photo credits: left, P. Kratina; right, Gerrit Velema.

tion at the lake level, however, is logistically impossible. Outdoor mesocosms cannot incorporate all physical components of natural ecosystems, but enable us to examine the effects of temperature on bottom-up and top-down processes in diverse systems experiencing natural levels of environmental variation.

\section{Sampling}

We sampled phytoplankton community biomass weekly by measuring the concentration of chlorophyll $a$ in the water column with in vivo fluorometry (Trilogy; Turner Designs, Sunnyvale, California, USA). Phytoplankton community composition was assessed from 50 $\mathrm{mL}$ samples collected at the end of the experiment and fixed with Lugol's iodine solution (5\%). At least 200 cells were counted in Utermöhl chambers under magnifications of 200 or $400 \times$. Taxa with very high densities were counted from 1.6-mL subsamples. These data were used to compare diversity (genus richness) and community taxonomic composition among the different treatment combinations. We also collected 10-L depth-integrated zooplankton samples on five sampling occasions across all seasons. Samples were pooled from multiple depths and locations within the tanks to minimize spatial variation within each tank, filtered through a $64-\mu \mathrm{m}$ sieve, and fixed with Lugol's solution. Zooplankters were identified to the lowest taxonomic resolution (usually genus), counted, and measured under $10 \times$ magnification, and biomass estimated with length-mass regressions (Dumont and Balvay 1979, McCauley 1984). Whole samples were analyzed and taxa with fewer than 500 individuals present were counted. Samples with more than 500 individuals of any taxa were subsampled so that at least 500 animals were counted to estimate zooplankton densities.

\section{Statistical analyses}

In order to estimate the effects of warming on bottomup and top-down perturbations on chlorophyll $a$ concentration, mean zooplankton community body size, and total zooplankton biomass, we constructed a linear mixed-effects model (LME) in which warming, nutrients, predators, and sampling occasion were fixed independent variables. Time was treated as a fixed factor because we were specifically interested in the seasonality of the effects. We treated the individual mesocosm as a random factor and accounted for temporal autocorrelation using AR(1) function (Pinheiro and Bates 2000). Both phytoplankton and zooplankton data were $\log _{e}$-transformed prior to the analyses to achieve normality of residuals and to improve homoscedasticity of variances.

One goal of our study was to test the interactive effects of the three press perturbations on the phytoplankton community. The magnitude of trophic cascades and eutrophication effects under warming indicate the extent to which the mean response of phytoplankton to top-down and bottom-up forces is altered by temperature. We used the linear mixed-effects model to test the significance of the interaction terms, and temporal patterns in the value of the interaction coefficient to indicate the seasonal dependence of synergistic and antagonistic effects of the treatments.

In addition to the mean response, we also assessed temporal stability of phytoplankton community biomass across all treatment combinations. Stability was calculated as the coefficient of variation $(\mathrm{CV})$ of the dispersion of the phytoplankton biomass observations through time around the arithmetic mean for each replicate and subsequently analyzed with a three-way ANOVA. CV has been commonly used as a metric of stability in recent terrestrial (Haddad et al. 2011), marine (Schindler et al. 2010), and freshwater studies (Howeth and Leibold 2010).

In order to investigate the potential mechanisms driving the variability of primary producer biomass, we assessed the effects of the three perturbations on community composition and taxonomic richness. Treatment effects on richness were analyzed using a three-way ANOVA, and taxonomic community compositions were 


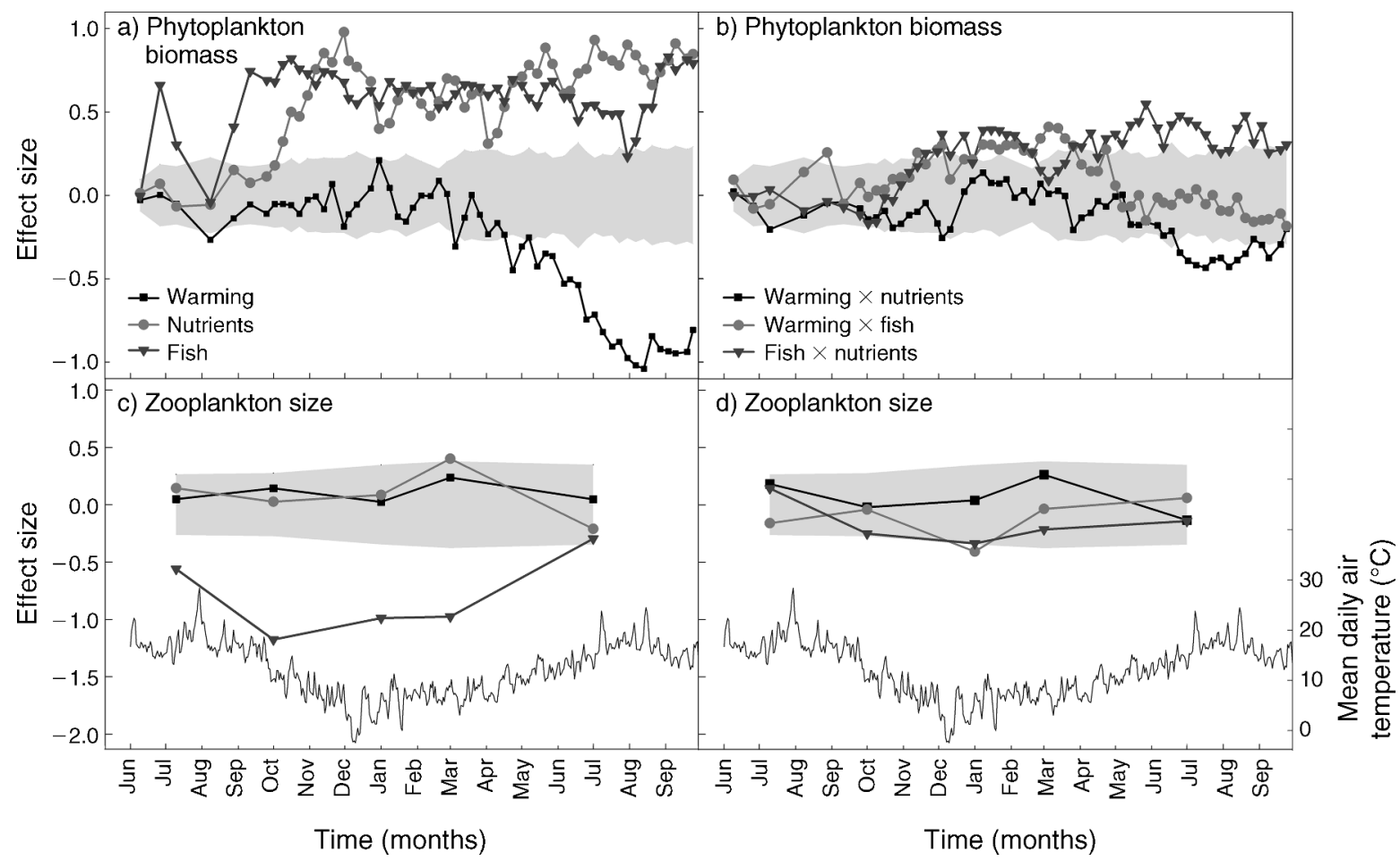

FIG. 1. Temporal effect of warming, fish, nutrients, and their interactions on $(a, b)$ phytoplankton biomass and (c, d) mean zooplankton body size. Each point represents the effect size measured as the factorial ANOVA parameter estimate for (a,c) the main effects and (b,d) two-way interactions on a particular sampling date. The gray zone represents the $95 \%$ confidence intervals around zero; therefore the effect is significant when the point lies outside the band. The black curve in panels (c) and (d) represents dynamics in the mean daily air temperature over the course of whole study (scale on right-hand axis).

analyzed using redundancy analysis (RDA; Legendre and Legendre 1998). RDA is a commonly used form of linear ordination that directly relates species composition to measured environmental factors (direct gradient analysis), which in our case were experimental treatments. Phytoplankton cell densities and zooplankton community biomass data were transformed using a Hellinger transformation to reduce the influence of outliers (Legendre and Gallagher 2001). Significance of each treatment and interaction was determined using Monte Carlo permutation tests on the results of the RDA. The responses of individual taxa to different treatment combinations are visualized in the redundancy ordination plot in the directions of a particular treatment or treatment interactions. All statistical analyses were performed in R 2.11.1 (R Development Core Team 2010), using R-packages nlme and vegan.

\section{RESULTS}

The treatments had both independent and interactive effects on primary producers that varied seasonally (Fig. 1; Appendix F). We observed strong positive main effects of fish via trophic cascades (linear mixed-effects model [LME], $F_{1,32}=82.177, P<0.001$; Fig. 1a) and of eutrophication (LME, $F_{1,32}=79.728, P<0.001$; Fig. 1a) on phytoplankton biomass across all seasons. In contrast, warming had a negative main effect on phytoplankton biomass (LME, $F_{1,32}=21.909, P<$ 0.001), which was most apparent during the second summer (Fig. 1a).

Our experimental approach allowed us to test cumulative impacts of multiple environmental forces on phytoplankton and zooplankton. We found that warming magnified the strength of trophic cascades from fish to phytoplankton and this effect varied over time (LME, warming $\times$ fish $\times$ time, $F_{59,1888}=2.385, P<$ 0.001 ; Fig. 1b). Warming reduced phytoplankton biomass during winter in the absence of fish, while the effects were weakly positive when fish were present (Appendix B). Fish also enhanced the positive effects of nutrients on phytoplankton biomass once nutrient effects became established in the winter (LME, fish $\times$ nutrients $\times$ time, $F_{59,1888}=3.550, P<0.001$; Fig. $1 b$ ). No interaction between warming and nutrients was seen until the second summer when dense algal blooms erupted in the fertilized mesocosms at ambient temperature, but not in the warmed mesocosms (LME, warming $\times$ nutrients $\times$ time, $F_{59,1888}=1.936, P<$ 0.001 ; Fig. 1b). Warming therefore enhanced the cascading effects of fish on phytoplankton in the winter and reduced the effects of nutrients in the summer, while fish increased sensitivity to eutrophication across all seasons. During the short period in winter $(\sim 7$ days $)$ when mesocosms were covered with ice, phytoplankton 

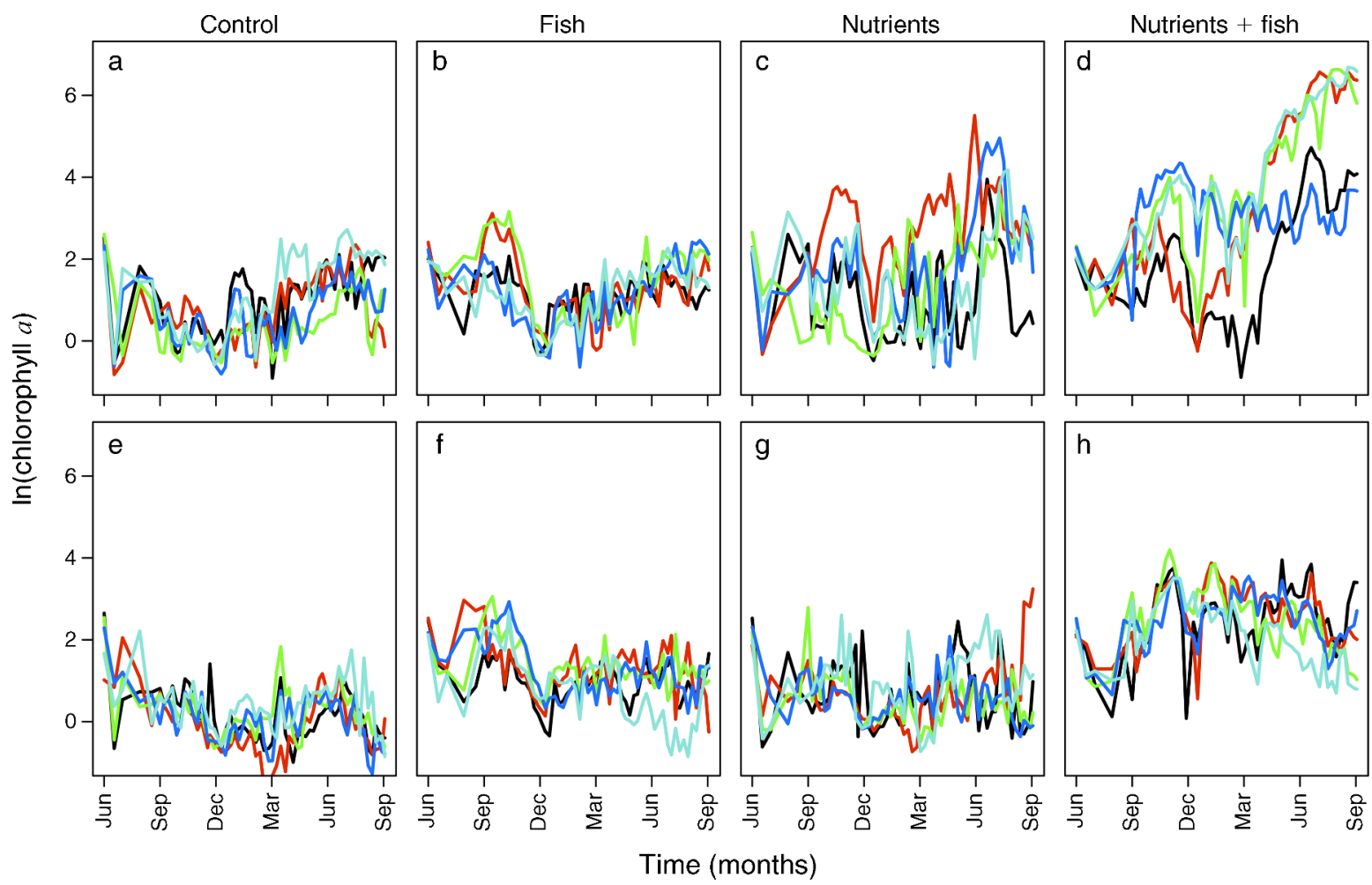

FIG. 2. Phytoplankton dynamics, measured as $\log _{e}$-transformed chlorophyll $a$ concentrations (originally measured in $\mu \mathrm{g} / \mathrm{L}$ ), across all eight treatment combinations $(n=5)$. Treatment combinations in the top row are (a) control, (b) fish, (c) nutrients, (d) nutrients and fish; the bottom row corresponds to the treatments above, but with addition of warming. Colored lines represent time series in individual mesocosms. The samples were collected at approximately one-week intervals for 16 months.

biomass declined in all treatments and increased again after the ice melted. The ice thickness was substantially lower in the warm $(2.35 \pm 0.22 \mathrm{~cm}$, mean $\pm \mathrm{SE}, n=20$ mesocosms) than in the ambient $(9.75 \pm 0.18 \mathrm{~cm}$, mean $\pm \mathrm{SE}, n=20$ ) mesocosms. Only two mesocosms had gaps in the ice cover and both were warmed.

Stickleback caused strong trophic cascades by reducing the mean body size of the zooplankton community (LME, $F_{1,32}=69.641, P<0.001$; Fig. 1c). This mechanism is consistent with whole-lake trophic cascade studies suggesting that the size structure of the zooplankton community is important for determining its grazing impact on phytoplankton (Carpenter et al. 1985). Warming strengthened the negative effect of stickleback on zooplankton body size in winter (Fig. 1d), but not in the other seasons, although there were no significant interactive effects of fish and warming on body size in the LME (Appendix G). Zooplankton community composition also confirmed that the effects of warming on grazer communities drove the stronger trophic cascades in winter. A significant main effect of warming was evident in winter and spring, with higher biomass of the large-bodied grazers Daphnia and Ceriodaphnia in warmed tanks (Appendix C).

In addition to the effects on mean phytoplankton biomass and zooplankton community composition, the treatments dramatically altered patterns of temporal variability of chlorophyll $a$ within mesocosms (Figs. 2 and 3; Appendix D). Eutrophication increased variation in phytoplankton community biomass (increased $\mathrm{CV}$, $F_{1,32}=16.973, P<0.001 ;$ Appendix D); however, warming substantially reduced the $\mathrm{CV}$ across all treatments $\left(F_{1,32}=8.314, P=0.007\right.$; Appendix D), with the strongest effect in the fertilized mesocosms (warming $\times$ nutrients, $F_{1,32}=18.839, P<0.001$; Appendix D). Warming dampened the effects of eutrophication on phytoplankton by reducing both the dense algal blooms that occurred in the second summer (chlorophyll $a$ up to $800 \mu \mathrm{g} / \mathrm{L}$ ), and the large, asynchronous fluctuations throughout the entire experiment in the tanks at ambient temperature (Fig. 2c, d). The scaling between the mean and standard deviation in chlorophyll $a$ concentration showed a flatter relationship in warmed mesocosms than those at ambient temperature (Fig. 3). Predators also reduced the temporal variability of phytoplankton biomass (reduced $\mathrm{CV}, F_{1,32}=9.196, P=0.005$; Appendix D).

We found that eutrophication significantly reduced the number of phytoplankton genera per sample $\left(F_{1,32}=\right.$ 9.196, $P=0.041$; Appendix E). In addition to the lower richness, the treatments had independent and interactive effects on phytoplankton taxonomic composition. The warming effect depended on both fish and nutrient treatments (Appendix H). The fertilized mesocosms with 


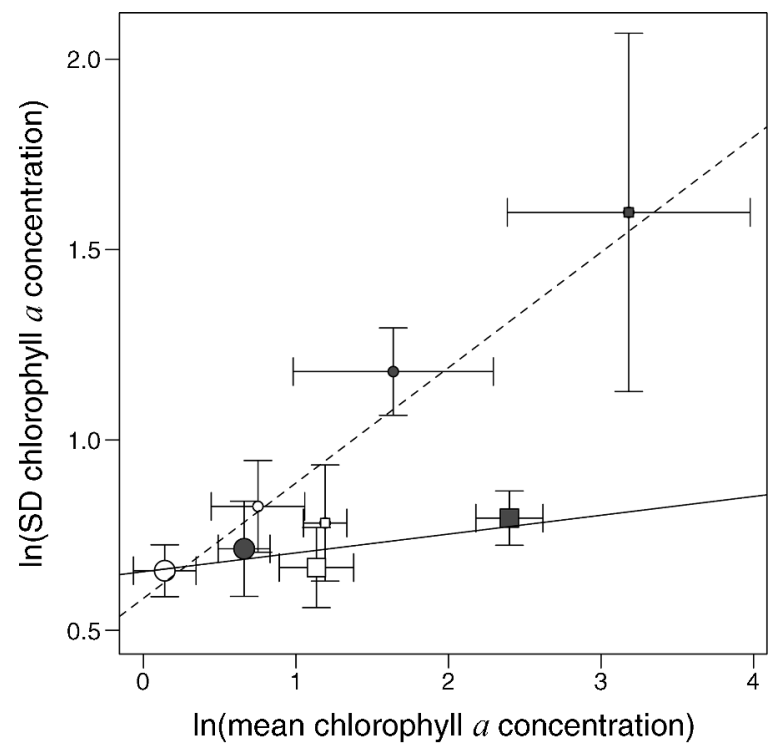

FIG. 3. Temporal variations of experimental phytoplankton communities relative to their means across all eight treatment combinations. The chlorophyll $a$ concentrations $(\mu \mathrm{g} / \mathrm{L})$ were $\log _{e}$-transformed prior to computing the standard deviations and arithmetic means. Error bars show \pm SE from the mean of five replicates. Large symbols represent warmed mesocosms; small symbols are mesocosms with ambient temperature. Squares indicate the presence of fish; circles are mesocosms without fish; solid symbols indicate fertilized mesocosms; open symbols indicate no additional nutrients. Linear regression fits for the mesocosms with ambient (dashed line) and $\sim 3^{\circ} \mathrm{C}$ above ambient (solid line) temperature are shown. The $y$-axis has data points for the mean SD (among mesocosms), but the vertical error bars are SE of the mean standard deviations.

ambient temperature were dominated by Palmellococcus (reaching densities up to $2 \times 10^{6}$ cells $/ \mathrm{mL}$ ) as indicated by the positive correlation of both Palmellococcus and nutrients with RDA Axis 2 (Fig. 4). The genus Palmellococcus was, however, negatively associated with all the warming treatment combinations (plotted in the opposite direction to the warming treatments; Fig. 4). Strong dominance by Palmellococcus might have contributed to higher community variation in the fertilized treatments at ambient but not high temperature if its numbers fluctuated more than other taxa (compare two polygons in Fig. 4; Appendix $\mathrm{H}$ ).

\section{DisCusSION}

Our results suggest that higher temperatures significantly alter the impact of top-down and bottom-up forces on the mean and temporal variation in phytoplankton biomass in shallow freshwater systems. Climate warming is one of a suite of anthropogenic perturbations taking place simultaneously in ecological systems (Tylianakis et al. 2008, Ormerod et al. 2010, Woodward et al. 2010). However, there is great uncertainty about the consequences of warming for community structure and variability, especially in the context of eutrophication or predator manipulation, two of the most pervasive and widespread human impacts on ecosystems (Carpenter et al. 1998, Estes et al. 2011). We found that warming made our experimental communities more susceptible to the cascading effects of predators, but reduced their sensitivity to nutrient enrichment.

The mechanism(s) behind the effects of warming on the variability of primary producers under eutrophication are not known but may reflect changes in physiology, algal community composition, or zooplankton grazing with temperature. We observed shifts in the taxonomic composition of phytoplankton among the treatments varying in their perturbation regime. We found that mesocosms with nutrients had lower taxonomic richness and were dominated by genus Palmellococcus (Chlorophyta) at the end of the experiment. Consistent with the paradox of enrichment (Rosenzweig 1971), eutrophication potentially contributed to large temporal fluctuations in the biomass of this dominant genus. Palmellococcus was, however, negatively associated with warming (Fig. 4), reaching densities three orders of magnitude lower (maximum of $1.3 \times 10^{3}$ cells $/ \mathrm{mL}$ ) in fertilized mesocosms under warming than at ambient temperature. Such changes in community composition may contribute to different variability in the combined phytoplankton biomass across treatments if the species that dominated the eutrophic tanks under warming show greater population dynamic stability than those in eutrophic tanks with ambient temperature.

Alternatively, if the metabolic demands of zooplankton increased faster with warming than their ingestion rates, then elevated temperature may have decreased zooplankton population growth rate, thereby dampening consumer-resource fluctuations (Rall et al. 2010). The stronger temperature dependence of metabolism than feeding could be a feature of many consumers that can contribute to stabilization of consumer-resource dynamics as temperatures rise (Rall et al. 2010, VucicPestic et al. 2011). Finally, the antagonistic interactions between eutrophication and warming in summer may have resulted from the high biomass of benthic diatoms and filamentous algae in these mesocosms that competed with limnetic algae (Trochine et al. 2011). Although not tested in this study, interactions between phytoplankton and bacteria (Fouilland and Mostajir 2010) or enhanced accumulation of organic matter under enrichment and warming (Wohlers et al. 2009) could have also contributed to the observed patterns in the phytoplankton biomass. Our novel finding is supported by a recent microcosm study indicating lower phytoplankton variability under elevated temperature (Burgmer and Hillebrand 2011); however, more empirical work is needed in order to discriminate among the proposed mechanisms in natural ecosystems. Furthermore, our results call into question the expectation that warming should generally lead to larger algae blooms and greater variability in 


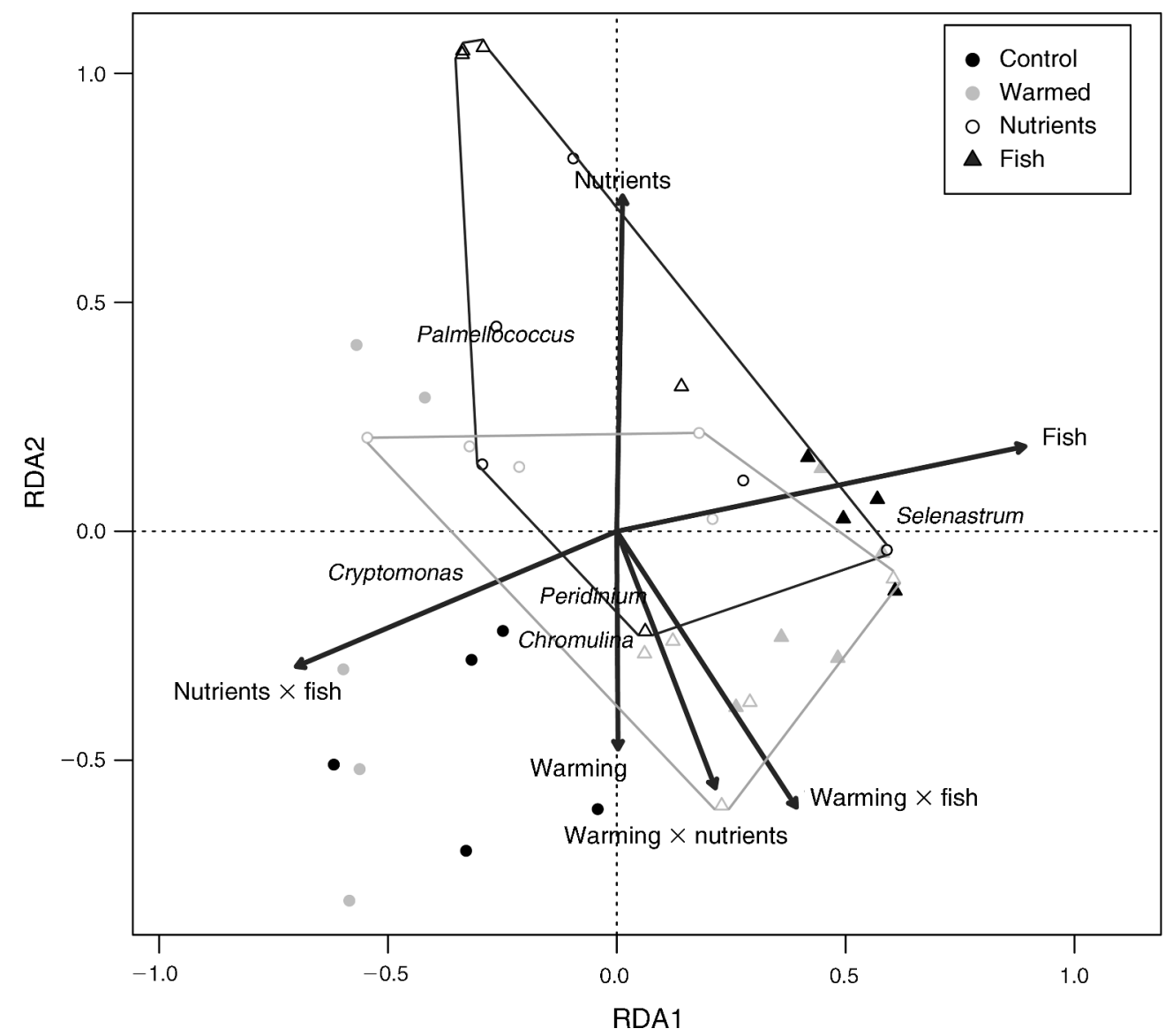

FIG. 4. The response of phytoplankton community composition to multiple perturbations analyzed by redundancy ordination (RDA) on Hellinger-transformed density data. All the two-way interaction terms and the main effects except of warming are significantly different $(P<0.05$; statistical summary is presented in Appendix $\mathrm{H})$. The black polygon represents mesocosms with nutrients and nutrient + fish treatments $(n=10)$ at ambient temperature; the gray polygon represents the same treatments in the warmed $\sim 3^{\circ} \mathrm{C}$ mesocosms $(n=10)$. All phytoplankton taxa were included in the analysis, but taxa centered on the origin are not shown to improve clarity.

aquatic production (Johnk et al. 2008), and correspond with recent findings from a marine system (Vidussi et al. 2011).

We showed that the combined effects of warming with both predator treatment and eutrophication on mean phytoplankton biomass varied over time. Higher temperatures led to stronger top-down effects in winter and reduced algal blooms under eutrophication in summer, but this latter effect was evident only during the second year. The period from June to September 2009 likely represents transient dynamics during which phytoplankton and zooplankton communities assembled and productivity was low relative to the summer of 2010 . Stronger trophic cascades with warming during winter months likely occurred because higher temperatures allowed large-bodied zooplankton to persist through the winter in the absence of stickleback, but not in their presence. Population growth and feeding rates of Daphnia are sensitive to cold water temperatures (Burns 1969) and warming likely increased Daphnia's activity throughout the winter, exerting the strong top-down control over phytoplankton in the tanks with no fish. Large zooplankton like Daphnia are often negatively affected by high temperatures during the summer (Moore et al. 1996), therefore we may have expected to see a weakening of trophic cascades by elevated temperatures during the warm months. However, this was not the case. Furthermore, the foraging rates of stickleback are also temperature dependent (Elliott and Leggett 1996), and increased activity of stickleback with warming likely contributed to the temporal dynamics in the strength of trophic cascades via increased predation on large cladocerans. Other ecological effects, such as phenological mismatch between phytoplankton bloom and the peak abundance of the key zooplankton herbivores or changes in the mixing events (Sommer et al. 1986) caused by warming may contribute to the seasonal patterns observed in natural systems.

Our results agree with studies in grasslands showing that elevated temperatures strengthened the cascading 
effects of spider predators on plant production (Barton et al. 2009). Warming has also been shown to reduce primary production at the base of aquatic food webs (Yvon-Durocher et al. 2010, Burgmer and Hillebrand 2011), with indirect effects propagating upward to higher consumers. In contrast, two mesocosm experiments did not detect any effects of warming on topdown or bottom-up processes (reviewed in Moss 2010), likely due to low phytoplankton biomass (on average threefold lower chlorophyll concentrations in the nutrient and predator treatments than in our study). However, our findings are in good agreement with theoretical expectations (Allen et al. 2005) and experimental findings of Yvon-Durocher et al. (2010) who showed reduced phytoplankton biomass and no change in zooplankton biomass due to warming in communities similar to ours. These studies measured the combined effects of warming and different local-scale perturbations, but did not include the temporal replication necessary to reveal the complex seasonal dynamics that we observed over many generations of primary producers. Our results add to a growing body of evidence that warming strengthens top-down control (O'Connor et al. 2009, Hoekman 2010), and provide novel evidence that the magnitude of this effect varies seasonally. In addition, the negative interaction between warming and nutrient effects on mean and variability of phytoplankton biomass has not to our knowledge been shown previously, and implies a shift toward stronger top-down and weaker bottom-up control with warming.

It is important to note the domain to which the conclusions from our experiment apply. The mesocosms contained simplified communities with limited physical complexity (e.g., no vertical stratification or habitat variability due to depth gradients or extensive macrophyte beds). However, taxonomic diversity and composition of zooplankton, phytoplankton, and zoobenthos were very similar to natural shallow ponds or the littoral zones of lakes. Recent research shows that mesocosms support multitrophic food webs that are structurally comparable to natural networks (Brown et al. 2011), suggesting that conclusions derived from mesocosm studies may reflect the responses of natural food webs to multiple perturbations (Woodward et al. 2010, Spivak et al. 2011). Although the use of such experimental mesocosms has been criticized for lack of applicability to natural systems (Carpenter 1996), we argue that the study included such diverse communities and experienced a sufficient range of environmental variability to serve as a strong test for the effects of warming on the transmission of top-down and bottom-up forces in food webs. The results indicate that the interactive effects of global- and local-scale perturbations on different elements of ecosystem stability are likely to be substantial. Whether similar effects will occur across a range of aquatic environments with different physical structures and environmental conditions remains to be seen; however, our results indicate that such effects may be sufficiently important to warrant further study. Furthermore, increased atmospheric $\mathrm{CO}_{2}$ may alter phytoplankton community palatability, either directly or in concert with increased temperatures. This could potentially modify the patterns we found based on the effects of temperature alone and remains a promising venue for future research.

Phytoplankton account for approximately one-half of all global primary production (Falkowski et al. 1998), but their abundance and variability is being altered by climate warming (Behrenfeld et al. 2006). Our results show that the effects of warming on phytoplankton may depend on local environmental conditions such as nutrient inputs and the intensity of grazing, as regulated by top predators. Therefore, in addition to the novel insights into the effects of climate warming on community variability, our results provide context for understanding variation among aquatic habitats in the effects of warming on primary production. The potential interactive effects of temperature and local-scale perturbations on freshwater food webs raise considerable uncertainty about the effects of future climate regimes. Our results point to a strong potential for both stabilizing and destabilizing effects of warming on the responsiveness of ecosystems to top-down and bottomup perturbations.

\section{ACKNOWLEDGMENTS}

P. Kratina and H. S. Greig contributed equally to this paper. We thank Annalise Barber, Andrew O'Farrell, Dylan Rawlyk, Matt Robinson, and Anne Rutherford for laboratory and field assistance; Wendy Palen for the use of water heaters; Elizabeth Wolkovich for advice with statistical analyses; Danusia Dolecki for phytoplankton identification; and Edd Hammill, Helmut Hillebrand, David Holway, Travis Ingram, Nathan Kraft, Mary O'Connor, Kaustuv Roy, Dolph Schluter, and Diane Srivastava for comments on the manuscript. P. Kratina was supported by the Natural Sciences and Engineering Research Council of Canada, H. S. Greig was supported by a New Zealand Foundation for Research, Science and Technology Postdoctoral Fellowship (UBX0901).

\section{Literature Cited}

Allen, A. P., J. F. Gillooly, and J. H. Brown. 2005. Linking the global carbon cycle to individual metabolism. Functional Ecology 19:202-213.

Barton, B. T., A. P. Beckerman, and O. J. Schmitz. 2009. Climate warming strengthens indirect interactions in an oldfield food web. Ecology 90:2346-2351.

Behrenfeld, M. J., R. T. O'Malley, D. A. Siegel, C. R. McClain, J. L. Sarmiento, G. C. Feldman, A. J. Milligan, P. G. Falkowski, R. M. Letelier, and E. S. Boss. 2006. Climatedriven trends in contemporary ocean production. Nature 444:752-755.

Bell, T., W. E. Neill, and D. Schluter. 2003. The effect of temporal scale on the outcome of trophic cascade experiments. Oecologia 134:578-586.

Brown, L. E., F. K. Edwards, A. M. Milner, G. Woodward, and M. E. Ledger. 2011. Food web complexity and allometric scaling relationships in stream mesocosms: implications for experimentation. Journal of Animal Ecology 80:884-895.

Burgmer, T., and H. Hillebrand. 2011. Temperature mean and variance alter phytoplankton biomass and biodiversity in a long-term microcosm experiment. Oikos 120:922-933. 
Burns, C. W. 1969. Relation between filtering rate, temperature, and body size in 4 species of Daphnia. Limnology and Oceanography 14:693-700.

Carpenter, S. R. 1996. Microcosm experiments have limited relevance for community and ecosystem ecology. Ecology 77:677-680.

Carpenter, S. R., N. F. Caraco, D. L. Correll, R. W. Howarth, A. N. Sharpley, and V. H. Smith. 1998. Nonpoint pollution of surface waters with phosphorus and nitrogen. Ecological Applications 8:559-568.

Carpenter, S. R., J. F. Kitchell, and J. R. Hodgson. 1985. Cascading trophic interactions and lake productivity. BioScience 35:634-639.

Darling, E. S., and I. M. Côté. 2008. Quantifying the evidence for ecological synergies. Ecology Letters 11:1278-1286.

Dumont, H. J., and G. Balvay. 1979. The dry weight estimate of Chaoborus flavicans (Meigen) as a function of length and instars. Hydrobiologia 64:139-145.

Elliott, J. K., and W. C. Leggett. 1996. The effect of temperature on predation rates of a fish (Gasterosteus aculeatus) and a jellyfish (Aurelia aurita) on larval capelin (Mallotus villosus). Canadian Journal of Fisheries and Aquatic Sciences 53:1393-1402.

Estes, J. A., et al. 2011. Trophic downgrading of planet Earth. Science 333:301-306.

Falkowski, P. G., R. T. Barber, and V. Smetacek. 1998. Biogeochemical controls and feedbacks on ocean primary production. Science 281:200-206.

Falkowski, P. G., and M. J. Oliver. 2007. Mix and match: how climate selects phytoplankton. Nature Reviews Microbiology 5:813-819.

Fouilland, E., and B. Mostajir. 2010. Revisited phytoplanktonic carbon dependency of heterotrophic bacteria in freshwaters, transitional, coastal and oceanic waters. FEMS Microbiology Ecology 73:419-429.

Haddad, N. M., G. M. Crutsinger, K. Gross, J. Haarstad, and D. Tilman. 2011. Plant diversity and the stability of foodwebs. Ecology Letters 14:42-46.

Harmon, L. J., B. Matthews, S. Des Roches, J. M. Chase, J. B. Shurin, and D. Schluter. 2009. Evolutionary diversification in stickleback affects ecosystem functioning. Nature 458:11671170 .

Hoekman, D. 2010. Turning up the heat: Temperature influences the relative importance of top-down and bottomup effects. Ecology 91:2819-2825.

Howeth, J. G., and M. A. Leibold. 2010. Species dispersal rates alter diversity and ecosystem stability in pond metacommunities. Ecology 91:2727-2741.

Johnk, K. D., J. Huisman, J. Sharples, B. Sommeijer, P. M. Visser, and J. M. Stroom. 2008. Summer heatwaves promote blooms of harmful cyanobacteria. Global Change Biology 14:495-512.

Legendre, P., and E. D. Gallagher. 2001. Ecologically meaningful transformations for ordination of species data. Oecologia 129:271-280.

Legendre, P., and L. Legendre. 1998. Numerical ecology. Second English edition. Elsevier, Amsterdam, The Netherlands.

McCauley, E. 1984. The estimation of the abundance and biomass of zooplankton in samples. Pages 228-265 in J. Downing and F. H. Rigler, editors. A manual on methods for the assessment of secondary productivity in fresh waters. Blackwell Scientific, Oxford, UK.

Montoya, J. M., and D. Raffaelli. 2010. Climate change, biotic interactions and ecosystem services. Philosophical Transactions of the Royal Society B 365:2013-2018.

Moore, M. V., C. L. Folt, and R. S. Stemberger. 1996. Consequences of elevated temperatures for zooplankton assemblages in temperate lakes. Archiv für Hydrobiologie 135:289-319.
Moss, B. 2010. Climate change, nutrient pollution and the bargain of Dr Faustus. Freshwater Biology 55:175-187.

O'Connor, M. I., M. F. Piehler, D. M. Leech, A. Anton, and J. F. Bruno. 2009. Warming and resource availability shift food web structure and metabolism. PLoS Biology 7:1-6.

Ormerod, S. J., M. Dobson, A. G. Hildrew, and C. R. Townsend. 2010. Multiple stressors in freshwater ecosystems. Freshwater Biology 55:1-4.

Petchey, O. L., P. T. McPhearson, T. M. Casey, and P. J. Morin. 1999. Environmental warming alters food-web structure and ecosystem function. Nature 402:69-72.

Pinheiro, J. C., and D. M. Bates. 2000. Mixed-effects models in $\mathrm{S}$ and S-PLUS. Springer-Verlag, New York, New York, USA.

R Development Core Team. 2010. R: a language and environment for statistical computing. R Foundation for Statistical Computing, Vienna, Austria. http://www. R-project.org

Rall, B. C., O. Vucic-Pestic, R. B. Ehnes, M. Emmerson, and U. Brose. 2010. Temperature, predator-prey interaction strength and population stability. Global Change Biology $16: 2145-2157$.

Ramanathan, V., and Y. Feng. 2008. On avoiding dangerous anthropogenic interference with the climate system: formidable challenges ahead. Proceedings of the National Academy of Sciences USA 105:14245-14250.

Rosenzweig, M. L. 1971. Paradox of enrichment: destabilization of exploitation in ecological time. Science 171:385-387.

Sala, O. E., et al. 2000. Global biodiversity scenarios for the year 2100. Science 287:1770-1774.

Schindler, D. E., R. Hilborn, B. Chasco, C. P. Boatright, T. P. Quinn, L. A. Rogers, and M. S. Webster. 2010. Population diversity and the portfolio effect in an exploited species. Nature 465:609-612.

Schindler, D. W. 1977. Evolution of phosphorus limitation in lakes. Science 195:260-262.

Schindler, D. W., K. G. Beaty, E. J. Fee, D. R. Cruikshank, E. R. DeBruyn, D. L. Findlay, G. A. Linsey, J. A. Shearer, M. P. Stainton, and M. A. Turner. 1990. Effects of climatic warming on lakes of the central boreal forest. Science 250:967-970.

Sommer, U., Z. M. Gliwicz, W. Lampert, and A. Duncan. 1986. The PEG-model of seasonal succession of planktonic events in fresh waters. Archiv für Hydrobiologie 106:433471.

Spivak, A. C., M. J. Vanni, and E. M. Mette. 2011. Moving on up: Can results from simple aquatic mesocosm experiments be applied across broad spatial scales? Freshwater Biology 56:279-291.

Trochine, C., M. Guerrieri, L. Liboriussen, M. Meerhoff, T. L. Lauridsen, M. Søndergaard, and E. Jeppesen. 2011. Filamentous green algae inhibit phytoplankton with enhanced effects when lakes get warmer. Freshwater Biology 56:541553.

Tylianakis, J. M., R. K. Didham, J. Bascompte, and D. A. Wardle. 2008. Global change and species interactions in terrestrial ecosystems. Ecology Letters 11:1351-1363.

Vasseur, D. A., and K. S. McCann. 2005. A mechanistic approach for modeling temperature-dependent consumerresource dynamics. American Naturalist 166:184-198.

Vidussi, F., B. Mostajir, E. Fouilland, E. Le Floc'h, J. Nouguier, C. Roques, P. Got, D. Thibault-Botha, T. Bouvier, and M. Troussellier. 2011. Effects of experimental warming and increased ultraviolet $\mathrm{B}$ radiation on the Mediterranean plankton food web. Limnology and Oceanography 56:206-218.

Vucic-Pestic, O., R. B. Ehnes, B. C. Rall, and U. Brose. 2011. Warming up the system: higher predator feeding rates but lower energetic efficiencies. Global Change Biology 17:13011310. 
Walther, G. R. 2010. Community and ecosystem responses to recent climate change. Philosophical Transactions of the Royal Society B 365:2019-2024.

Walther, G. R., E. Post, P. Convey, A. Menzel, C. Parmesan, T. J. C. Beebee, J.-M. Fromentin, O. Hoegh-Guldberg, and F. Bairlein. 2002. Ecological responses to recent climate change. Nature 416:389-395.

Winder, M., J. E. Reuter, and S. G. Schladow. 2009. Lake warming favours small-sized planktonic diatom species. Proceedings of the Royal Society B 276:427-435.

Wohlers, J., A. Engel, E. Zöllner, P. Breithaupt, K. Jürgens, H.-G. Hoppe, U. Sommer, and U. Riebesell. 2009. Changes in biogenic carbon flow in response to sea surface warming. Proceedings of the National Academy of Sciences USA 106:7067-7072.

Woodward, G., D. M. Perkins, and L. E. Brown. 2010. Climate change and freshwater ecosystems: impacts across multiple levels of organization. Philosophical Transactions of the Royal Society B 365:2093-2106.

Yvon-Durocher, G., J. M. Montoya, M. Trimmer, and G. Woodward. 2010. Warming alters the size spectrum and shifts the distribution of biomass in freshwater ecosystems. Global Change Biology 17:1681-1694.

\section{Supplemental Material}

\section{Appendix A}

Mean daily water temperature in heated and unheated mesocosms over the course of the experiment (Ecological Archives E093124-A1).

\section{Appendix B}

Interactive effect of warming and predation during winter (Ecological Archives E093-124-A2).

\section{Appendix C}

The response of zooplankton community composition to different treatments (Ecological Archives E093-124-A3).

\section{Appendix D}

Temporal variability of experimental phytoplankton communities across all treatment combinations as illustrated by coefficient of variation in chlorophyll $a$ concentrations (Ecological Archives E093-124-A4).

\section{Appendix E}

Phytoplankton genus richness as a function of treatment combinations (Ecological Archives E093-124-A5).

\section{Appendix F} A6).

Linear mixed effects model summary statistics for the $\log _{e}$-transformed phytoplankton biomass (Ecological Archives E093-124-

\section{Appendix G}

Linear mixed-effects model summary statistics for the $\log _{e}$-transformed mean zooplankton community body size (Ecological Archives E093-124-A7).

\section{Appendix $\mathbf{H}$}

Summary statistics for the redundancy analysis (RDA) on Hellinger-transformed phytoplankton taxonomic composition data (Ecological Archives E093-124-A8). 